\title{
Double kissing crush bifurcation stenting: step-by-step troubleshooting
}

\author{
Allison B. Hall ${ }^{1}$, MD; Ivan Chavez ${ }^{1}$, MD; Santiago Garcia ${ }^{1}$, MD; Mario Gössl ${ }^{1}$, MD; Anil Poulose ${ }^{1}$, MD; \\ Paul Sorajja ${ }^{1}$, MD; Yale Wang ${ }^{1}$, MD; Yves Louvard ${ }^{2}$, MD; Yiannis S. Chatzizisis ${ }^{3}$, MD, PhD; \\ Subhash Banerjee ${ }^{4}, \mathrm{MD}$; Iosif Xenogiannis ${ }^{1}, \mathrm{MD}$; M. Nicholas Burke ${ }^{1}$, MD; Emmanouil S. Brilakis ${ }^{1 *}$, MD, PhD \\ 1. Minneapolis Heart Institute, Abbott Northwestern Hospital, Minneapolis, MN, USA; 2. Institut Cardiovasculaire Paris Sud, \\ Massy, France; 3. Cardiovascular Division, University of Nebraska Medical Center, Omaha, NE, USA; 4. UT Southwestern \\ Medical Center, Dallas, TX, USA
}

A list of study collaborators can be found in the Appendix paragraph.

This paper also includes supplementary data published online at: https://eurointervention.pcronline.com/doi/10.4244/EIJ-D-19-00721

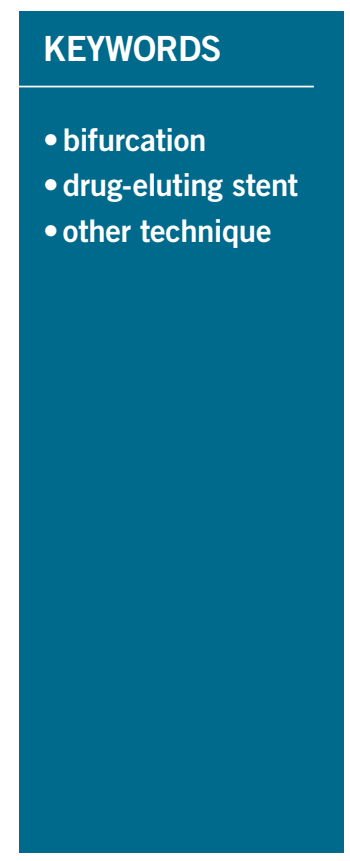

\section{Abstract}

The double kissing crush (DK crush) is the most studied two-stent coronary bifurcation stenting strategy. While published data support its use, DK crush can be challenging to perform. In this review we provide a detailed step-by-step description and troubleshooting for each stage of the DK crush technique.

*Corresponding author: Minneapolis Heart Institute, 920 E 28th Street \#300, Minneapolis, MN 55407, USA.

E-mail: esbrilakis@gmail.com 


$\begin{array}{ll}\text { Abbreviations } \\ \text { DK } & \text { double kissing } \\ \text { IVUS } & \text { intravascular ultrasound } \\ \text { LM } & \text { left main } \\ \text { MC } & \text { microcatheter } \\ \text { MI } & \text { myocardial infarction } \\ \text { MV } & \text { main vessel } \\ \text { OCT } & \text { optical coherence tomography } \\ \text { PCI } & \text { percutaneous coronary intervention } \\ \text { POT } & \text { proximal optimisation technique } \\ \text { SB } & \text { side branch } \\ \text { SKS } & \text { simultaneous kissing stent } \\ \text { TAP } & \text { T and protrusion }\end{array}$

\section{Introduction}

Provisional stenting is the preferred and recommended stenting strategy for most coronary bifurcation lesions ${ }^{1,2}$; however, twostent techniques are often needed in lesions with a large, diseased side branch (SB). The most commonly used two-stent coronary bifurcation stenting strategies are $\mathrm{T}$-stenting, $\mathrm{T}$ and protrusion (TAP), culotte, classic crush, mini crush and double kissing (DK) crush.

DK crush is the most extensively studied two-stent bifurcation technique (Supplementary Table 1 ) $^{3-9}$. DK crush was superior to classic crush (in the DKCRUSH-I trial) ${ }^{3}$ and to provisional stenting (in the DKCRUSH-II trial) ${ }^{4}$ in true bifurcation lesions. DK crush was superior to both culotte (in the DKCRUSH-III trial) and provisional stenting (in the DKCRUSH-V trial) ${ }^{8}$ in left main (LM) bifurcations. A recent meta-analysis suggested that DK crush may be superior to several other techniques due to more frequent ability to perform final kissing (99\% rate vs $80-85 \%)^{10}$. DK crush can be technically challenging, limiting its adoption. We review potential challenges and solutions for each step of the DK crush technique.

\section{ANGIOGRAPHIC ASSESSMENT}

The first step in percutaneous coronary intervention (PCI) of any bifurcation lesion is to perform a thorough analysis of the target lesion, often using intracoronary imaging with intravascular ultrasound (IVUS) or optical coherence tomography (OCT), assessing the size of the main vessel (MV) and the SB, degree of MV and SB disease, presence and extent of calcification and the bifurcation angulation (Figure 1, Figure 1A).

\section{ARTERIAL ACCESS AND GUIDE SELECTION}

DK crush can be performed using radial access and 6 Fr guide catheters. In complex bifurcations, however (such as those with severe calcification and tortuosity), using a large guide catheter ( 7 or $8 \mathrm{Fr}$ ) and femoral access can improve support and facilitate the procedure. Moreover, guides that provide strong support are preferred, such as Amplatz left (AL) guides for the right coronary artery and extra backup (XB or EBU) guides for the LM.

\section{Steps of the DK crush technique (Figure 2)} STEP 1. MAIN VESSEL AND SIDE BRANCH WIRING

\section{(Figure 1B, Figure 3-Figure 6).}

The first step of DK crush is to wire both the MV and the SB.

\section{STEP 2. MAIN VESSEL AND SIDE BRANCH PREPARATION (Figure 1B, Figure 1C, Figure 7).}

The second step of the DK crush is to adequately prepare both the MV and the SB, usually with balloon angioplasty, in order to facilitate stent delivery and optimal stent expansion.

\section{STEP 3. SIDE BRANCH STENTING WITH SHORT PROTRUSION INTO THE MAIN VESSEL (Figure 1D, Figure 1E). CHALLENGES AND SOLUTIONS}

\section{a) Failure to deliver the SB stent}

The most common causes of failure to deliver a stent in the SB are either inadequate lesion preparation, or severe tortuosity. Hence, the first step is additional SB dilation or other plaque modification (Figure 7).

If an appropriately sized balloon cannot cross into the SB, the first step is to use a small, highly deliverable balloon, such as the $1.0 \mathrm{~mm}$ Sapphire Pro (OrbusNeich, Fort Lauderdale, FL, USA), 1.5 mm TAKERUTM (Terumo, Tokyo, Japan), or THREADER ${ }^{\mathrm{TM}}$ (Boston Scientific, Marlborough, MA, USA) balloon. If such a balloon crosses, incrementally larger balloons can then be advanced until the SB is adequately dilated. If even the lowest profile balloons do not cross into the SB, a microcatheter (MC) can often be advanced into the SB, modifying the ostium and allowing subsequent balloon crossing.

If the above techniques fail, a more supportive wire, such as the Wiggle wire (Abbott Vascular, Santa Clara, CA, USA) can be advanced in the SB (often through an MC) to facilitate delivery. Balloon crossing can also be facilitated by increasing guide support, for example by using a guide catheter extension, or the side branch anchor technique (Figure 8). The anchor balloon should ideally be inflated in an MV segment that will subsequently be stented, to minimise the risk of MV injury and restenosis. Guide catheter extensions are usually advanced over a small balloon (usually $2.0 \mathrm{~mm}$ diameter) placed halfway within and halfway distal to the guide catheter extension. The balloon is inflated at low pressure (6-10 atm) and then deflated, while simultaneously advancing the guide extension over the deflating balloon, which allows easier advancement of the guide extension. It is often necessary to advance the guide extension distally to achieve optimal support.

If the aforementioned steps fail, the risks and benefits of SB atherectomy should be weighed; if the branch is severely angulated or of smaller calibre, it may be best to avoid atherectomy. If the branch is large and has a favourable angle, atherectomy can be considered, either after removal of the MV wire before atherectomy, or while covering the MV wire with an MC or guide catheter extension to minimise the risk of MV injury. In heavily calcified bifurcation lesions, particularly in distal LM PCI, upfront atherectomy, of both branches, can facilitate equipment delivery and stent expansion ${ }^{11}$. 


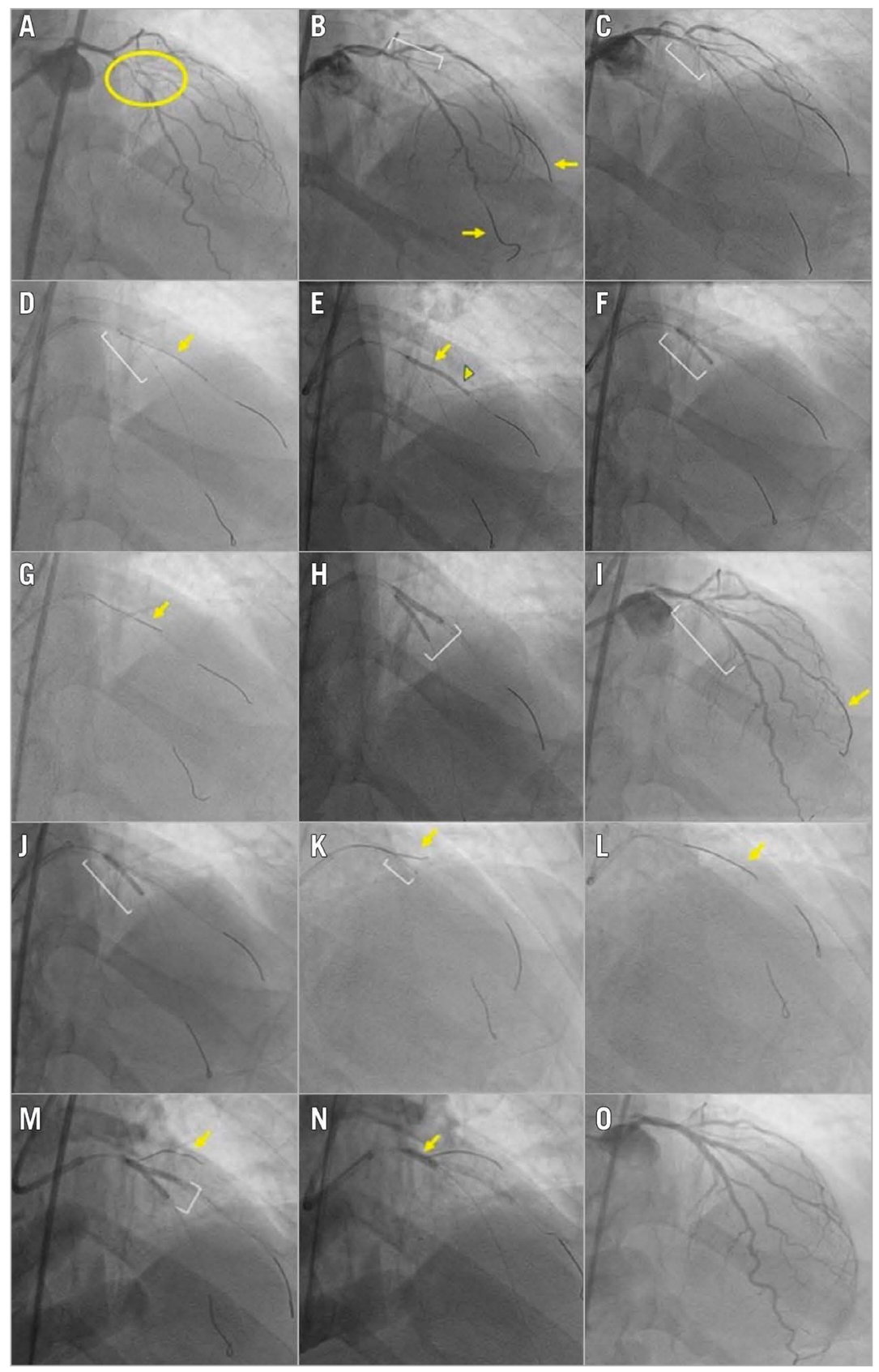

Figure 1. Angiographic case example of a bifurcation lesion treated successfully with the double kissing crush technique. A) Medina 1,1,1 bifurcation lesion (yellow circle) with significant disease involving the mid left anterior descending (LAD) artery and the bifurcating second diagonal branch. The bifurcation angle is $<70^{\circ}$. The side branch supplies a large myocardial segment. B) Wires (yellow arrows) are placed in both the LAD (main vessel) and the diagonal branch (side branch). A balloon (white bracket) is placed in the diagonal branch for predilation. C) A balloon (white bracket) is placed in the LAD for predilation. D) A stent (yellow arrow) is positioned in the diagonal branch. A balloon (white bracket) is pre-positioned in the LAD prior to deploying the diagonal stent to allow subsequent crushing of the diagonal branch stent. E) The diagonal branch stent is deployed (yellow arrow). The angiographic result in the diagonal is optimised (for example to correct stent underexpansion indicated by arrowhead) prior to crushing the side branch stent. F) The LAD balloon (white bracket) is inflated, crushing the diagonal stent. G) A new wire (yellow arrow) is used to re-wire the crushed diagonal branch stent and the original diagonal wire is removed. H) The first simultaneous kissing balloon inflation (white bracket) is performed in the LAD and diagonal branch. I) The LAD stent is positioned (white bracket); the diagonal wire (yellow arrow) is not removed. J) The LAD stent (white bracket) is deployed, followed by proximal optimisation technique (POT) of the main vessel stent (not imaged). K) Due to difficulty re-wiring the diagonal branch, a Twin-Pass ${ }^{\circledR}$ Torque (Teleflex) dual-lumen microcatheter (white bracket) is used, with successful advancement of a new wire (yellow arrow) through the over-the-wire port of the device. L) The jailed diagonal wire (yellow arrow) is removed. M) The second simultaneous kissing balloon inflation (white bracket) is performed. A wire (yellow arrow) was placed in a more proximal first diagonal to maintain access to the vessel. N) Repeat POT is performed, with balloon inflation (yellow arrow) within the proximal main branch (LAD) stent up to the carina. O) Excellent final angiographic result. 


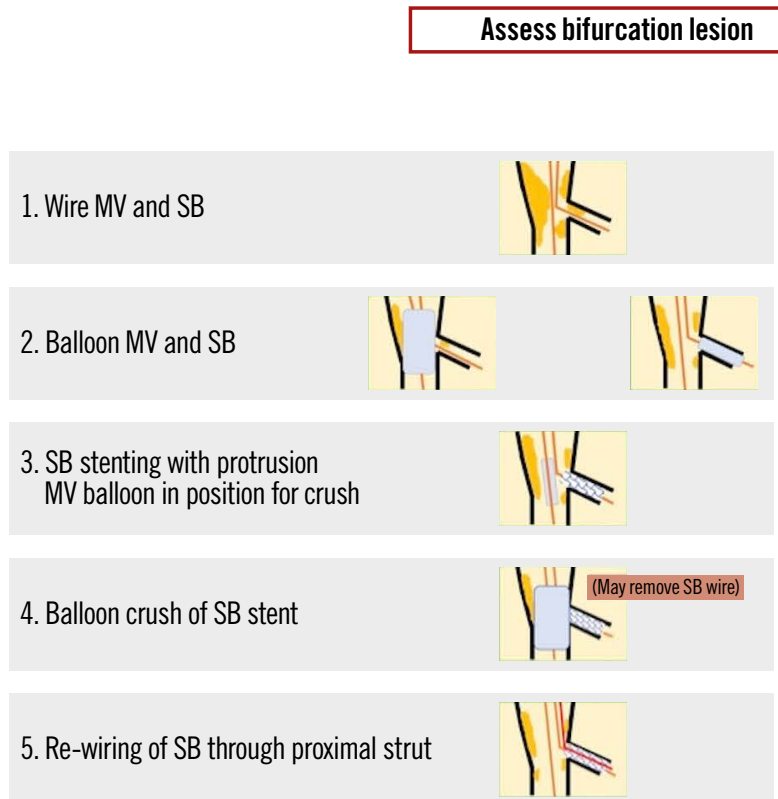

Final result

\section{$1 \frac{1}{5}$}

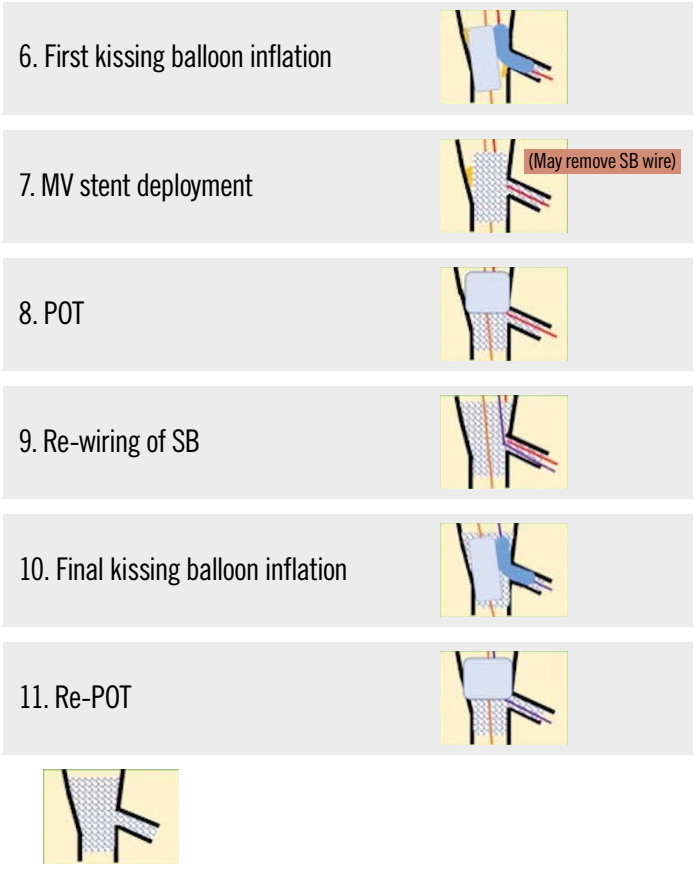

Figure 2. The steps of the double kissing crush bifurcation stenting technique. The numbers to the left of each image correspond to the step number and affiliated troubleshooting information provided for each step within the body of the text.

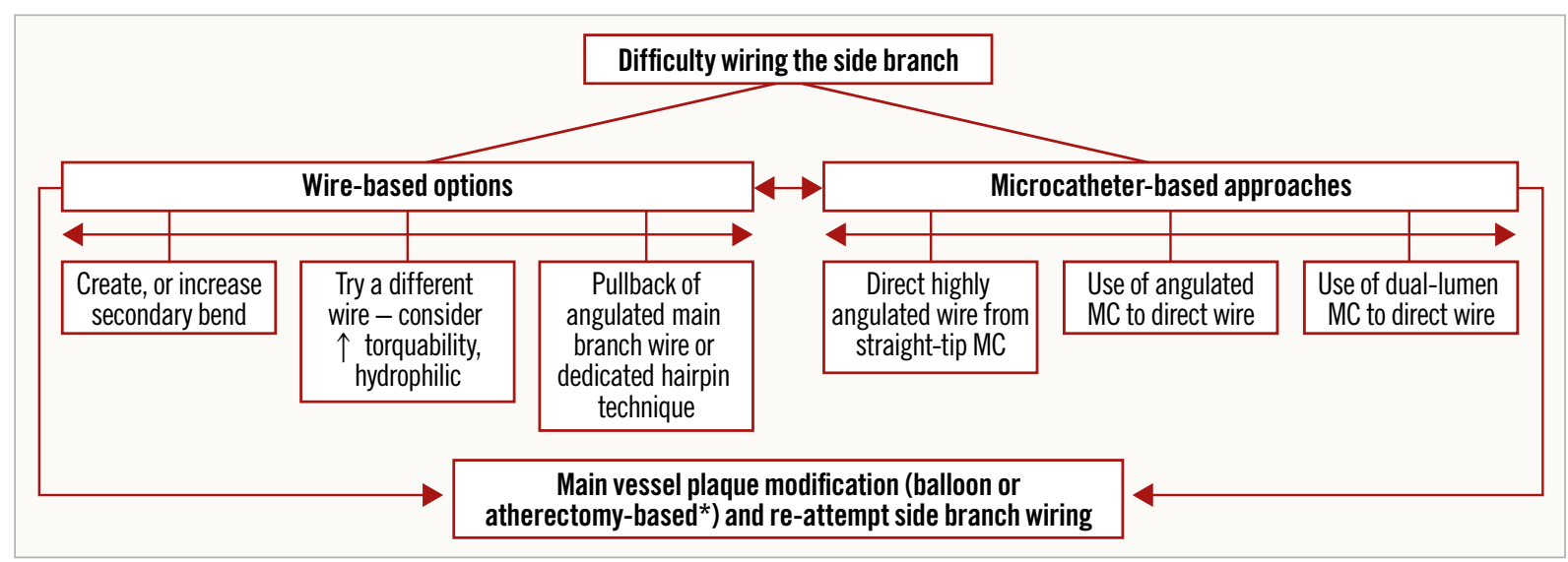

Figure 3. Algorithm for approaching a side branch which is difficult to wire. *atherectomy only if no new stents yet placed. MC: microcatheter

\section{b) How far should the SB stent protrude into the MV?}

The SB stent should be positioned approximately $2-3 \mathrm{~mm}$ into the main vesse ${ }^{12}$. Attempting to position the stent only 1-2 mm inside the MV may lead to missing the SB ostium, which will then necessitate placement of another stent. Longer SB stent protrusion is preferable to insufficient protrusion. The goal is to achieve complete coverage of the SB ostium, while minimising stent protrusion into the MV. The "independent hand" technique (Figure 9) and visualisation in multiple planes can facilitate optimal SB stent placement.

\section{c) Failure to deliver MV balloon before SB stent deployment}

The balloon that will be used for SB stent crushing should be inserted in the MV before deploying the SB stent, as MV balloon advancement after the SB stent deployment can be challenging or fail (Figure 1D, Figure 1F). The balloon used for crushing should be sized 1:1 to the distal MV. Alternatively, or if the stent appears inadequately crushed after this balloon sizing, a larger balloon, sized 1:1 to the proximal MV reference, could be used, ensuring that the distal end of the balloon is proximal to the carina to avoid injury of the distal MV. 


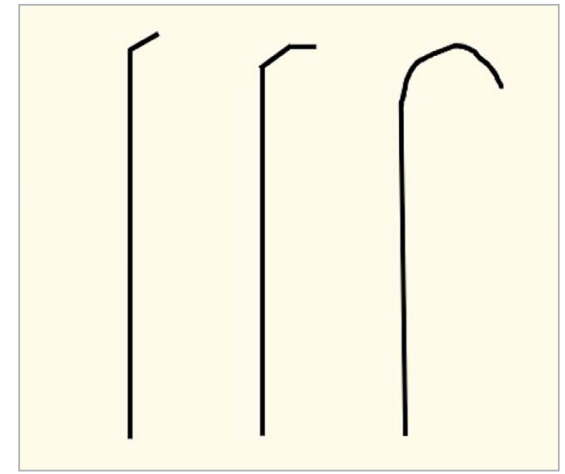

Figure 4. Examples of wire tip shapes that can be formed to facilitate difficult side branch wiring.

\section{d) Premature SB stent crushing}

Before crushing the SB stent (Figure 1F), angiography (and possibly intravascular imaging) should be performed to ensure optimal SB stent deployment, as it can be challenging to advance equipment into the SB after crushing. Any SB stent edge complications,

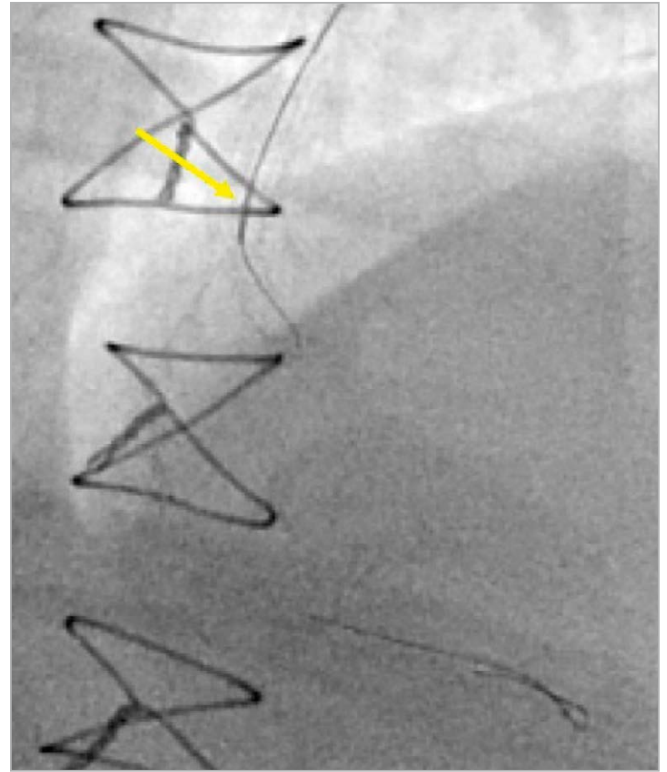

Figure 6. A microcatheter (yellow arrow) is used to direct a wire into an obtuse marginal branch.

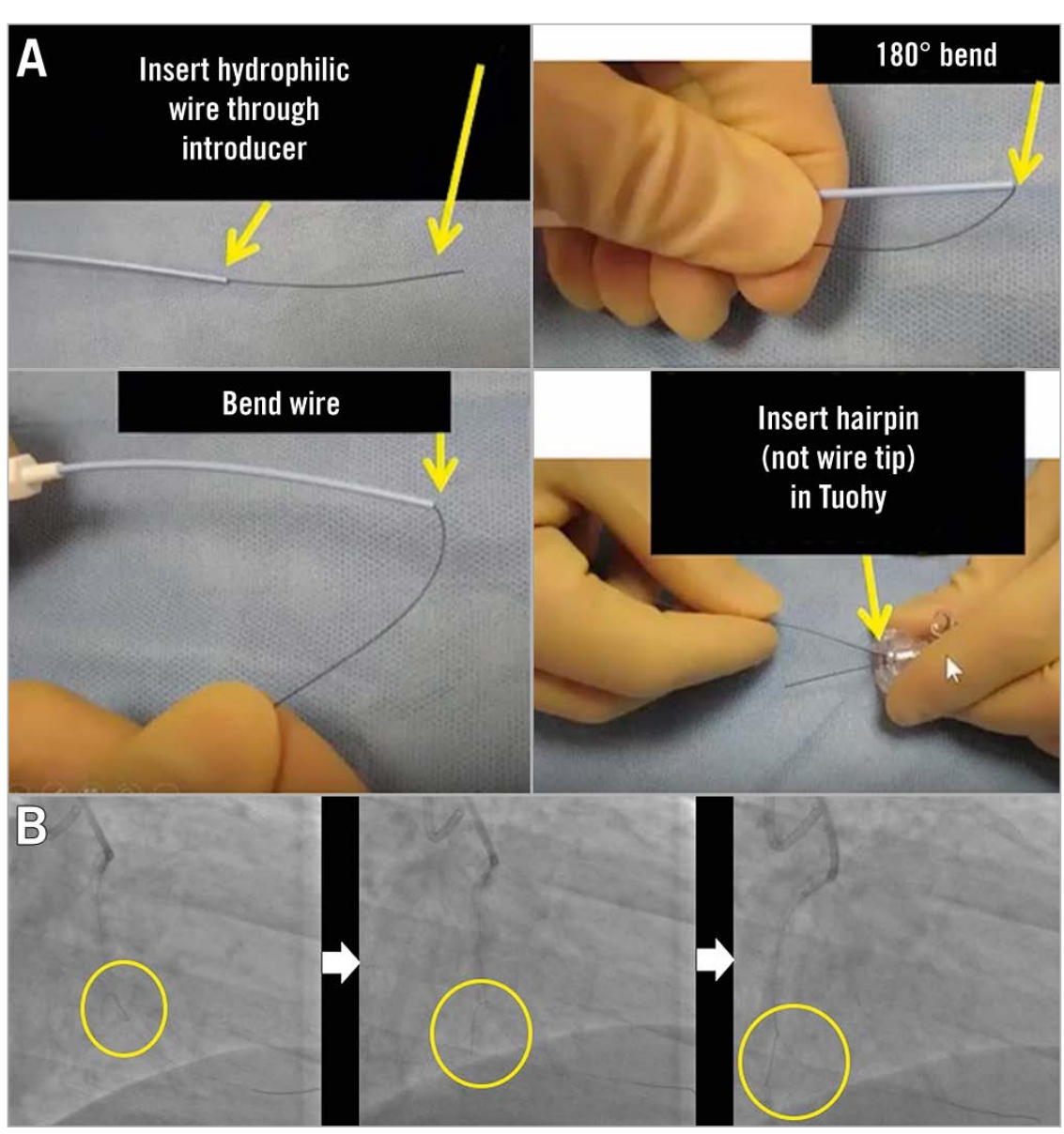

Figure 5. The "hairpin" wire technique. A) Illustration of how to form a "hairpin" on a coronary wire. B) A hairpin shape on a wire is used to enter an acute marginal branch. The hairpin is advanced past the branch and is then withdrawn, unfolding and entering the branch.

Reproduced with permission from: Brilakis ES. Manual of Coronary Chronic Total Occlusion Interventions. A Step-By-Step Approach. 2nd edition. Amsterdam, the Netherlands: Elsevier; 2017. 


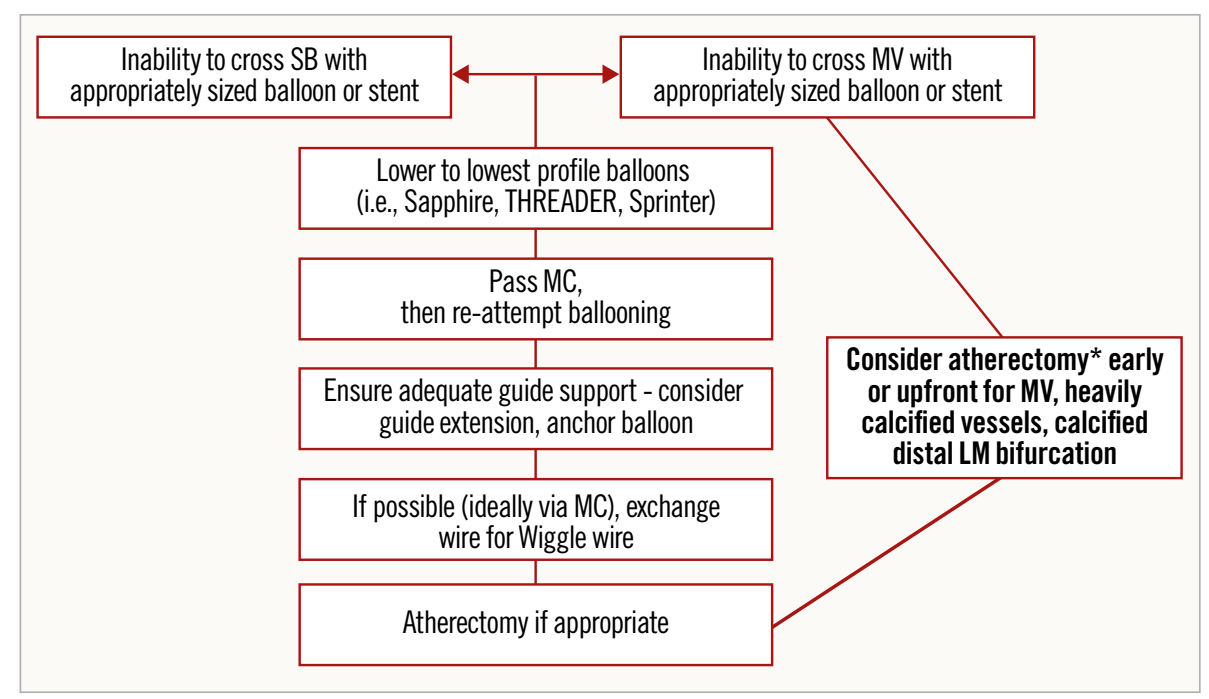

Figure 7. Algorithmic approach in case of failure to advance a balloon or stent into the main branch or side branch of a coronary bifurcation. *atherectomy only if no new stents yet placed. LM: left main; MC: microcatheter; MV: main vessel; SB: side branch

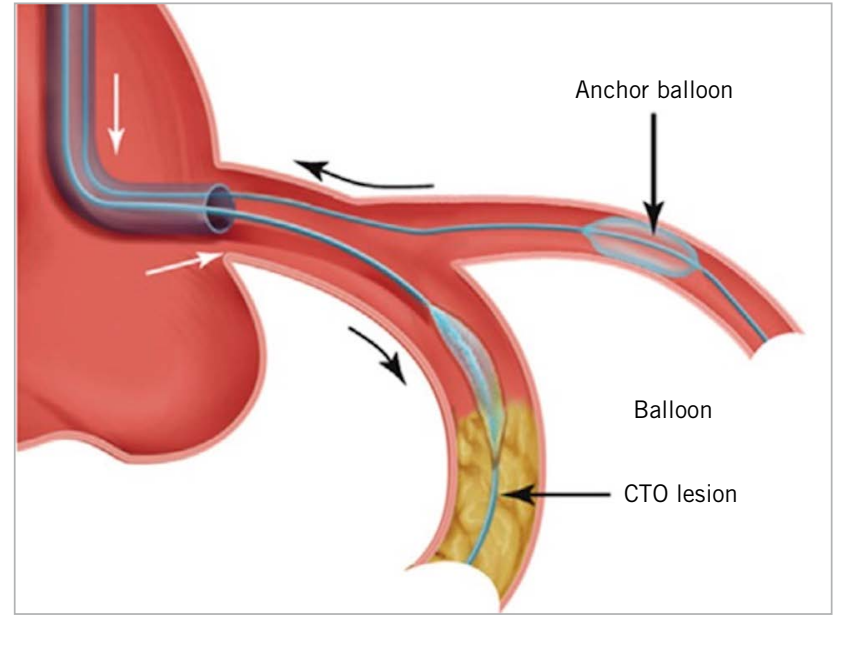

Figure 8. Use of an anchor balloon in a side branch to increase support for advancement of equipment in the main branch in chronic total occlusion (CTO) percutaneous coronary intervention (PCI).

This technique can be adapted for use when equipment is difficult to advance into the main branch or even side branch, when performing double kissing crush bifurcation stenting.

downstream geographical miss, or more distal SB disease should be treated prior to SB crushing (Figure 1E).

\section{STEP 4. BALLOON CRUSHING OF SIDE BRANCH STENT.}

\section{CHALLENGES AND SOLUTIONS}

\section{a) Jailing the SB wire}

Many interventional cardiologists are reticent to deploy stents in the MV when there is a wire in the $\mathrm{SB}$, due to concerns about SB wire entrapment. However, leaving the SB guidewire in place when deploying the MV stent could help preserve SB patency and facilitate SB rewiring, which could be particularly useful when the
SB has a highly angulated take-off or severe ostial disease. Some operators jail an MC or balloon over the SB wire; however, this is not generally recommended.

\section{b) SB wire selection}

While wire entrapment may be rare, damage to jailed SB wires can occur ${ }^{13}$. One microscopy-based study of jailed wires showed that mild damage occurred in only 2 of 115 polymer-jacketed wires, versus 63 of 120 (55\%) of non-polymer-jacketed wires, two of which developed internal fracturing ${ }^{13}$. Longer jailing length was associated with higher likelihood of wire damage, and wiring the SB was quicker when a polymer-jacketed wire was used ${ }^{13}$. This study also showed no significant difference in secondary outcomes of periprocedural myocardial infarction (MI) and major adverse events during follow-up. In summary, jailing polymer-jacketed guidewires is acceptable.

\section{c) Inability to remove the jailed SB guidewire}

Although initial retraction is part of the process of realising that a wire is stuck in the SB, forceful pulling of an entrapped wire should be avoided, as it may lead to wire fracture and unravelling, which could necessitate cardiac surgery for removal. The best way to free an entrapped SB guidewire is to advance a balloon or MC over it as far distally as possible before retracting it, which in most cases leads to guidewire retrieval. Inflating a small balloon advanced as distally as possible can also help remove an entrapped guidewire.

d) Risk of longitudinal deformation of an ostial stent or ostial coronary dissection upon withdrawal of a jailed SB guidewire

Retraction of the jailed SB guidewire may lead to forward movement of the guide catheter, potentially causing longitudinal stent deformation $^{12}$ or ostial coronary dissection, that could be catastrophic in the LM. As a result, backward traction (or sometimes near complete disengagement) of the guide catheter from the coronary ostium is recommended prior to withdrawing a jailed SB wire. 


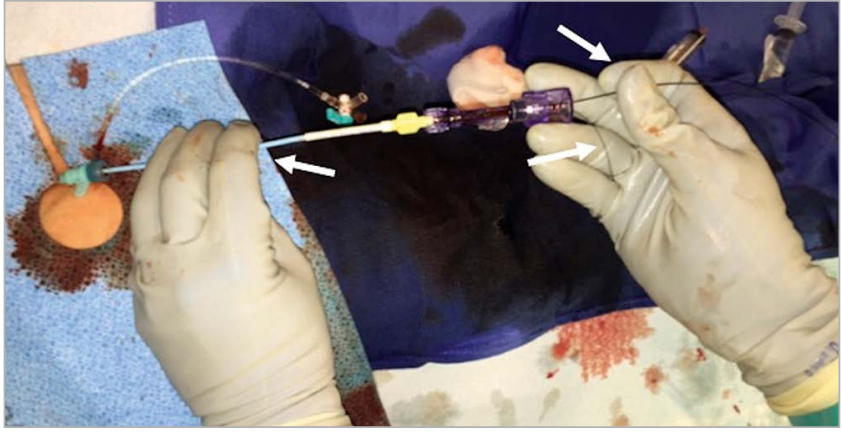

Figure 9. The "independent hand" technique, that allows careful and precise placing of a stent at the side branch ostium with slight protrusion in the main vessel. It is also a useful technique for difficult angioplasty equipment delivery in general. The white arrow on the left shows how the operator's left fingers are used to hold and, as needed, adjust the guide position. The white arrow on the right shows that the coronary guidewire is held between the 4th and 5th digits of the right hand. The operator's right index finger and thumb are used to pinch and advance or retract the balloon or microcatheter, while the 3rd and 4th digits of the right hand are used to grasp the circumference of the Tuohy.

\section{STEP 5. RE-WIRING THE SIDE BRANCH THROUGH THE CRUSHED SIDE BRANCH STENT (Figure 1G).}

\section{CHALLENGES AND SOLUTIONS}

\section{a) Proximal or distal rewiring}

In contrast to provisional stenting in which re-crossing through a distal strut is desirable, initial re-crossing the crushed SB stent in the DK crush technique should be done through a proximal stent strut to minimise the risk of SB stent deformation ${ }^{12}$ (Figure 10). A theoretical exception could include bifurcations with a particularly narrow angle for which proximal re-crossing may shift more struts towards the MV, leading to a less desirable, longer neocarina. The $2^{\text {nd }}$ recrossing should be done through a distal strut.

\section{b) The wire will not re-cross the crushed SB stent}

Side branch rewiring can be challenging. When encountering difficulty, use of an algorithmic approach that modifies the type, shape and manipulation of the guidewire and/or the use of microcatheters can facilitate success (Figure 3).

If wiring with workhorse guidewires fails, different wire types, such as hydrophilic-coated, polymer-jacketed or occasionally dedicated chronic total occlusion wires, can be used. Changing the guidewire tip shape can also help, for example by placing a short and acute angulation, two distal bends, or in some cases, a much broader curvature (Figure 4). Once the wire catches the SB ostium, it is important to keep the tip free: after initial careful torqueing to secure position, more rapid torqueing or "twiddling" of the wire may help to advance it distally into the SB. Special caution should be used when advancing through heavily diseased segments to reduce the risk of dissection. Conveniently, wires with a significant secondary bend are prone to prolapsing into

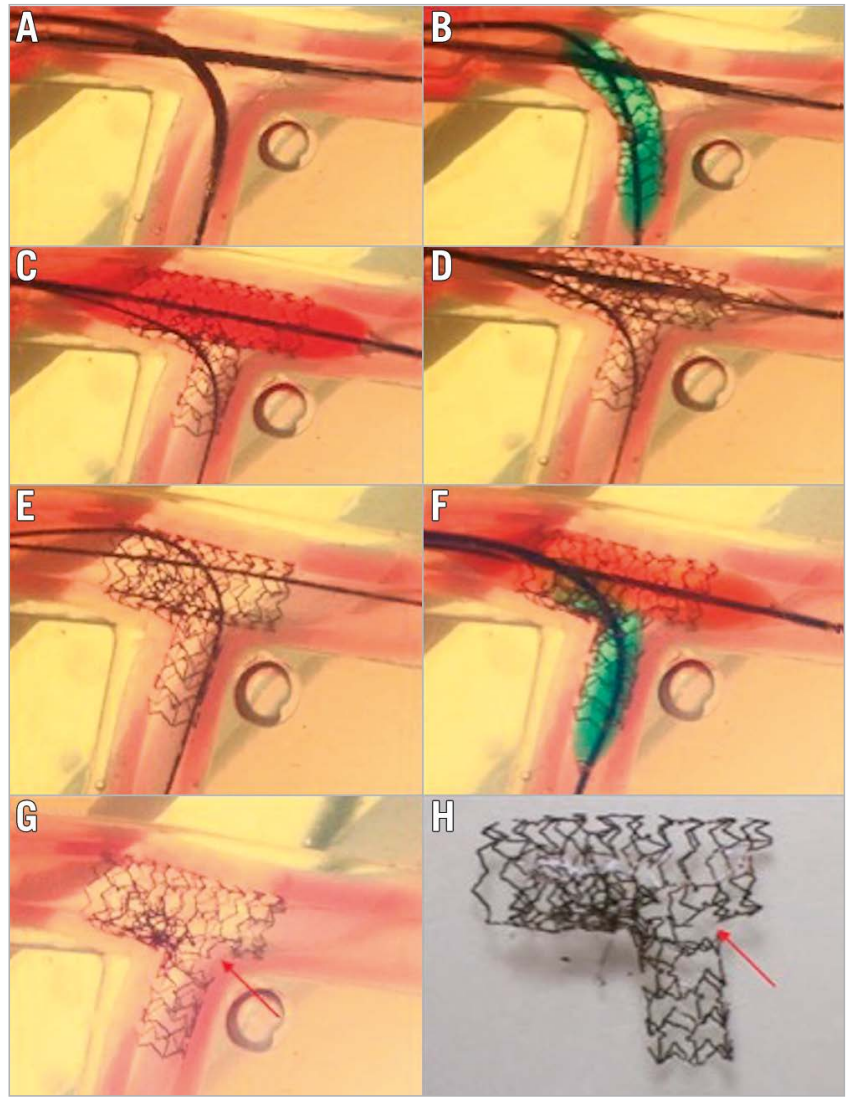

Figure 10. Drawback of too distal SB re-crossing in the classic crush technique. A) Position of MV and SB stents. B) SB stent deployment. C) MV stent deployment to crush the SB stent. D) Gap formation near the carina. E) Distal SB re-crossing, wire going between the $S B$ stent and vessel wall. F) Final kissing balloon inflation. G) \& H) Leaving a significant gap near the carina. MV: main vessel; $S B$ : side branch Reprinted from Zhang JJ and Chen SL. Classic crush and DK crush stenting techniques. EuroIntervention. 2015;11:V102-V105. With permission from Europa Digital \& Publishing.

a knuckle, which can facilitate distal advancement while avoiding engagement of other small branches.

Another technique for wiring highly angulated SBs is to advance a guidewire with a large bend placed on the distal tip distally in the MV, past the SB ostium and withdraw it. As the bend unfolds, it often engages the SB ostium. A more extreme variation of this technique is the "hairpin" wire technique (Figure 5A, Figure 5B).

Achieving successful SB wire position may require the use of an $\mathrm{MC}$ to provide wire support and allow easy re-shaping of wires and protrusion of highly angulated wire tips into the SB without first having to navigate the highly bent wire down the MV (Figure 6). Any straight tip MC can be used for this purpose. For a particularly severe SB take-off angle, angulated steerable microcatheters can be useful, such as the Venture ${ }^{\circledR}$ (Teleflex, Minneapolis, MN, USA) or SwiftNINJA ${ }^{\circledR}$ (Merit Medical, South Jordan, UT, USA). Fixed angulation microcatheters, such as SuperCross ${ }^{\mathrm{TM}} 90^{\circ}$ or $120^{\circ}$ (Teleflex, Wayne, PA, USA) can also be helpful. 
Another MC-based option is using a dual-lumen MC advanced over the MV wire, with subsequent advancement of the SB wire out through the over-the-wire port (Figure 1K).

Lastly, another option is modification of the MV with balloon angioplasty or further crushing of the SB stent, in the hope of altering the geometry of the bifurcation carina, facilitating SB wiring.

\section{STEP 6. FIRST KISSING BALLOON INFLATION (Figure 1H). CHALLENGES AND SOLUTIONS}

\section{a) Optimising balloon selection}

Determining the distal MV reference diameter and SB diameter is necessary for choosing balloon sizes for the kissing inflation. This is best accomplished with intravascular imaging (especially for very large or small vessels), if feasible.

The simultaneously inflated balloons have an effective diameter proximal to the bifurcation that is equal to two thirds of the sum of each balloon diameter (Finet's law): (diameter proximal MV $)=0.67 \times($ diameter SB + diameter distal MV $)$. Noncompliant balloons are preferred, but may be harder to deliver, in which case compliant balloons can be used. A "two-step kiss" is recommended, first performing individual high-pressure ( $\geq 20 \mathrm{~atm})$ balloon inflations in each branch, followed by kissing balloon inflation at lower pressure (12-14 atm). The goal of the first kissing balloon inflations in DK crush is to achieve optimal stent coverage of the SB ostium.

While the above method is probably the most common approach, there are other variants of the two-step kiss such as the modified kissing balloon inflation approach where the SB is first inflated to $12 \mathrm{~atm}$, then partly deflated back to $4 \mathrm{~atm}$ with simultaneous inflation of the MV balloon to $12 \mathrm{~atm}$, which may reduce proximal stent deformation ${ }^{14}$.

\section{b) Failure to re-cross the crushed SB stent with a balloon}

The same steps described in section 3a above (Figure 7) apply. The initial approach is to use a low-profile balloon but, if this fails, rewiring the SB may facilitate re-crossing.

\section{STEP 7. MAIN VESSEL STENTING ACROSS THE SB (Figure 1I,} Figure 1J).

\section{CHALLENGES AND SOLUTIONS}

\section{a) Should the SB wire be removed prior to MV stent deployment?}

In most cases, the SB wire is removed to avoid "sandwiching" it between two layers of stent, which could lead to entrapment.

b) The MV stent will not advance and is catching on the SB stent

Difficulty advancing the MV stent can be approached in a similar fashion to that outlined in step $3 \mathrm{a}$ above, usually with repeat balloon dilation of the MV.

c) How should the MV stent be placed in relation to the SB stent?

The optimal MV stent length proximal and distal to the SB takeoff is dependent partially on the extent of MV disease. The MV stent should be long enough to cover the crushed segment of the SB stent completely and also to allow the proximal optimisation technique (POT) (i.e., at least 6-8 $\mathrm{mm}$ proximal to the carina) ${ }^{12}$.
STEP 8. PROXIMAL OPTIMISATION TECHNIQUE (POT)

(Figure 1N).

POTENTIAL CHALLENGES AND TIPS

\section{a) Why POT?}

Because the MV stent is sized to match the distal MV diameter, the proximal stent may require post-dilation with a balloon sized $1: 1$ to the proximal MV to achieve adequate proximal stent expansion. If the proximal segment of the MV stent is not adequately expanded, SB rewiring may cross behind the MV stent, potentially leading to MV deformation. Sufficient expansion of the proximal MV stent also enlarges the opening of the struts that cover the SB ostium ${ }^{1,12}$.

b) Where should the balloon be positioned during POT relative to the bifurcation carina?

At least 6-8 mm of MV stent are needed proximal to the SB origin to allow positioning of the balloon proximally for POT. The distal balloon marker should be at the carina ${ }^{12}$

\section{STEP 9. RE-WIRING THE SB THROUGH THE MV AND SB STENTS (Figure 1K, Figure 1L). \\ CHALLENGES AND SOLUTIONS}

\section{a) The wire will not cross}

The approach is as outlined in step 5b (Figure 3).

\section{STEP 10. SECOND KISSING BALLOON INFLATION (Figure 1M). CHALLENGES AND SOLUTIONS}

\section{a) An appropriately sized balloon will not pass into the $S B$, the MV or both}

The approach is similar to that outlined in step 3a (Figure 7). However, atherectomy should not be performed at this stage with both stents in place. Guide catheter extensions can enhance support. Advancing an $\mathrm{MC}$ into the $\mathrm{SB}$ can create enough space to allow subsequent equipment delivery and wire exchange for a more supportive wire.

\section{STEP 11. REPEAT PROXIMAL OPTIMISATION TECHNIQUE (RE-POT).}

\section{CHALLENGES AND SOLUTIONS}

\section{a) Why re-POT?}

Repeating POT at the end of the DK crush helps to maintain circular geometry through the bifurcation and reduce SB ostium strut obstruction and strut malapposition ${ }^{12}$. Unlike the first POT, it may be best to keep the distal balloon marker for the re-POT just proximal to the carina to avoid disruption of the bifurcation stent architecture.

b) The balloon will not cross into the proximal MV stented segment

The approach is similar to that outlined in step 3a, except for atherectomy.

\section{STEP 12. REVIEWING THE FINAL RESULT (Figure 10). CHALLENGES AND SOLUTIONS}

a) Intracoronary imaging should be performed to ensure adequate stent expansion and SB ostial coverage as well as to detect complications such as edge dissection. 
b) The angiogram and/or intracoronary imaging should be reviewed to ensure no evidence of proximal or distal edge dissections.

c) The angiogram should be reviewed carefully to ensure that there is no evidence of distal wire perforation. This is particularly relevant to DK crush as advancing wiring and equipment can be challenging during the various steps of the procedure, potentially leading to distal perforation.

Moving image 1 illustrates a summarising, step-by-step angiographic case example of the completion of a DK crush bifurcation stenting.

\section{Conclusion}

"No pain, no gain" has been used to describe DK crush, as it entails multiple steps and can be challenging to perform, while at the same time it provides optimal long-term outcomes. Awareness of the potential challenges and solutions, as described in this article, can help to minimise the "pain", while maintaining the "gain".

\section{Appendix. Study collaborators}

Michael Mooney, MD; Minneapolis Heart Institute, Abbott Northwestern Hospital, Minneapolis, MN, USA. Jay H. Traverse, MD; Minneapolis Heart Institute, Abbott Northwestern Hospital, Minneapolis, MN, USA.

\section{Conflict of interest statement}

A. Hall reports speaker fees/honoraria from Medtronic, OpSens Medical and Cardiovascular Innovations Foundation. M.N. Burke reports being a consultant for Merit Medical and a speaker for OpSens Medical. E. Brilakis reports consulting/speaker honoraria from Abbott Vascular, American Heart Association (Associate Editor, Circulation), Biotronik, Boston Scientific, Cardiovascular Innovations Foundation (board of directors), CSI, Elsevier, GE Healthcare, Infraredx, Medtronic, and Teleflex, research support from Regeneron and Siemens, and being a shareholder in MHI Ventures. Y. Chatzizisis reports consulting/speaker honoraria from Boston Scientific, research support from Boston Scientific and Medtronic, and being on the board of directors of the European Bifurcation Club. S. Banerjee reports institutional grants from Boston Scientific, Abbott Vascular, and Chiesi, and consulting fees from AstraZeneca. The other authors have no conflicts of interest to declare.

\section{References}

1. Ng AK, Jim MH. Percutaneous Coronary Intervention for Bifurcation: How Can We Outperform the Provisional Strategy? Clin Cardiol. 2016;39:684-91.

2. Brilakis ES, Burke MN, Banerjee S. DK-Crush Should Become Preferred Strategy for Treating Unprotected LM Bifurcation Lesions: No Pain, No Gain. J Am Coll Cardiol. 2017;70:2618-20.

3. Chen SL, Zhang JJ, Ye F, Chen YD, Patel T, Kawajiri K, Lee M, Kwan TW, Mintz G, Tan HC. Study comparing the double kissing (DK) crush with classical crush for the treatment of coronary bifurcation lesions: the DKCRUSH-1 Bifurcation Study with drug-eluting stents. Eur J Clin Invest. 2008;38:361-71.
4. Chen SL, Santoso T, Zhang JJ, Ye F, Xu YW, Fu Q, Kan J, Paiboon C, Zhou Y, Ding SQ, Kwan TW. A randomized clinical study comparing double kissing crush with provisional stenting for treatment of coronary bifurcation lesions: results from the DKCRUSH-II (Double Kissing Crush versus Provisional Stenting Technique for Treatment of Coronary Bifurcation Lesions) trial. J Am Coll Cardiol. 2011;57: 914-20.

5. Chen SL, Xu B, Han YL, Sheiban I, Zhang JJ, Ye F, Kwan TW, Paiboon C, Zhou YJ, Lv SZ, Dangas GD, Xu YW, Wen SY, Hong L, Zhang RY, Wang HC, Jiang TM, Wang Y, Chen F, Yuan ZY, Li WM, Leon MB. Comparison of double kissing crush versus Culotte stenting for unprotected distal left main bifurcation lesions: results from a multicenter, randomized, prospective DKCRUSH-III study. J Am Coll Cardiol. 2013; 61:1482-8.

6. Chen SL, Xu B, Han YL, Sheiban I, Zhang JJ, Ye F, Kwan TW, Paiboon C, Zhou YJ, Lv SZ, Dangas GD, Xu YW, Wen SY, Hong L, Zhang RY, Wang HC, Jiang TM, Wang Y, Sansoto T, Chen F, Yuan ZY, Li WM, Leon MB. Clinical Outcome After DK Crush Versus Culotte Stenting of Distal Left Main Bifurcation Lesions: The 3-Year Follow-Up Results of the DKCRUSH-III Study. JACC Cardiovasc Interv. 2015;8: 1335-42.

7. Ye F, Chen SL, Zhang JJ, Zhu ZS, Kan J, Tian NL, Lin S, Liu ZZ, You W, Xu HM, $\mathrm{Xu}$ J. Hemodynamic changes of fractional flow reserve after double kissing crush and provisional stenting technique for true bifurcation lesions. Chin Med J. 2012;125: 2658-62.

8. Chen SL, Zhang JJ, Han Y, Kan J, Chen L, Qiu C, Jiang T, Tao L, Zeng H, Li L, Xia Y, Gao C, Santoso T, Paiboon C, Wang Y, Kwan TW, Ye F, Tian N, Liu Z, Lin S, Lu C, Wen S, Hong L, Zhang Q, Sheiban I, Xu Y, Wang L, Rab TS, Li Z, Cheng G, Cui L, Leon MB, Stone GW. Double Kissing Crush Versus Provisional Stenting for Left Main Distal Bifurcation Lesions: DKCRUSH-V Randomized Trial. J Am Coll Cardiol. 2017;70:2605-17.

9. Chen SL, Ye F, Zhang JJ, Xu T, Tian NL, Liu ZZ, Lin S, Shan SJ, Ge Z, You W, Liu YQ, Qian XS, Li F, Yang S, Kwan TW, Xu B, Stone GW. Randomized Comparison of FFR-Guided and Angiography-Guided Provisional Stenting of True Coronary Bifurcation Lesions: The DKCRUSH-VI Trial (Double Kissing Crush Versus Provisional Stenting Technique for Treatment of Coronary Bifurcation Lesions VI). JACC Cardiovasc Interv. 2015;8:536-46.

10. Crimi G, Mandurino-Mirizzi A, Gritti V, Scotti V, Strozzi C, de Silvestri A, Montalto C, di Giacomo C, d'Ascenzo F, Repetto A, Ferlini M, Marinoni B, Ferrario M, de Servi S, Visconti LO, Klersy C. Percutaneous Coronary Intervention Techniques for Bifurcation Disease: Network Meta-analysis Reveals Superiority of Double-Kissing Crush. Can J Cardiol. 2020;36:906-14.

11. Chambers JW, Warner C, Cortez J, Behrens AN, Wrede DT, Martinsen BJ. Outcomes after Atherectomy Treatment of Severely Calcified Coronary Bifurcation Lesions: A Single Center Experience. Cardiovasc Revasc Med. 2019;20:569-72.

12. Rab T, Sheiban I, Louvard Y, Sawaya FJ, Zhang JJ, Chen SL. Current Interventions for the Left Main Bifurcation. JACC Cardiovasc Interv. 2017;10:849-65.

13. Pan M, Ojeda S, Villanueva E, Chavarria J, Romero M, Suarez de Lezo J, Mazuelos F, Segura J, Carrasco F, Hidalgo F, Lopez Aguilera J, Rodriguez S, Puente M, Suarez de Lezo J. Structural Damage of Jailed Guidewire During the Treatment of Coronary Bifurcation Lesions: A Microscopic Randomized Trial. JACC Cardiovasc Interv. 2016;9:1917-24.

14. Murasato Y, Finet G, Foin N. Final kissing balloon inflation: the whole story. EuroIntervention. 2015;11 Suppl V:V81-5.

\section{Supplementary data}

Supplementary Table 1. Summary of the findings of the double kissing crush (DKCRUSH I-VI) trials.

Moving image 1. Abridged images of steps from a DK crush twostent bifurcation PCI for a Medina 1,1,1 bifurcation lesion in the mid left anterior descending artery.

The supplementary data are published online at:

https://eurointervention.pcronline.com/

doi/10.4244/EIJ-D-19-00721 


\section{Supplementary data}

\section{Supplementary Table 1. Summary of the findings of the double kissing crush (DKCRUSH I-VI)}

trials.

\begin{tabular}{|c|c|c|c|c|c|c|}
\hline & DKCRUSH-I [3] & DKCRUSH-II [4] & DKCRUSH-III $[5,6]$ & $\begin{array}{c}\text { DKCRUSH-IV } \\
\text { [7] }\end{array}$ & $\begin{array}{c}\text { DKCRUSH-V } \\
\text { [8] }\end{array}$ & DKCRUSH-VI [9] \\
\hline \# of patients & 311 & 370 & 419 & 75 & 482 & 320 \\
\hline Trial design & $\begin{array}{l}\text { Multicentre, } \\
\text { prospective, } \\
\text { randomised } \\
\text { controlled trial }\end{array}$ & $\begin{array}{l}\text { Multicentre, } \\
\text { prospective, } \\
\text { randomised } \\
\text { controlled trial }\end{array}$ & $\begin{array}{l}\text { Multicentre, } \\
\text { prospective, } \\
\text { randomised } \\
\text { controlled trial }\end{array}$ & $\begin{array}{l}\text { Single-centre, } \\
\text { prospective, } \\
\text { randomised } \\
\text { controlled trial }\end{array}$ & $\begin{array}{l}\text { Multicentre, } \\
\text { prospective, } \\
\text { randomised } \\
\text { controlled } \\
\text { trial }\end{array}$ & $\begin{array}{l}\text { Multicentre, } \\
\text { prospective, } \\
\text { randomised } \\
\text { controlled trial }\end{array}$ \\
\hline Comparison & $\begin{array}{l}\text { Classic crush vs DK } \\
\text { crush in true } \\
\text { bifurcation lesions } \\
\text { (LAD-diagonal; } \\
\text { distal LM; LCx-OM; } \\
\text { distal RCA) }\end{array}$ & $\begin{array}{c}\text { DK crush or } \\
\text { provisional stenting } \\
\text { in true bifurcation } \\
\text { lesions }\end{array}$ & $\begin{array}{l}\text { DK crush vs culotte } \\
\text { for unprotected } \\
\text { distal LM bifurcation } \\
\text { lesions }\end{array}$ & $\begin{array}{l}\text { Haemodynami } \\
\text { c changes in } \\
\text { FFR with DK } \\
\text { crush vs } \\
\text { provisional } \\
\text { stenting for } \\
\text { true } \\
\text { bifurcation } \\
\text { lesions }\end{array}$ & $\begin{array}{l}\text { DK crush vs } \\
\text { provisional } \\
\text { stenting for } \\
\text { distal LM } \\
\text { bifurcation } \\
\text { lesions }\end{array}$ & $\begin{array}{l}\text { Angiographic vs } \\
\text { FFR-guided SB } \\
\text { stenting in } \\
\text { provisional } \\
\text { stenting of true } \\
\text { bifurcation } \\
\text { lesions }\end{array}$ \\
\hline $\begin{array}{l}\text { Primary } \\
\text { endpoint }\end{array}$ & $\begin{array}{l}\text { Major adverse } \\
\text { cardiac events } \\
\text { (MACE) including } \\
\text { MI, cardiac death, } \\
\text { target lesion } \\
\text { revascularisation } \\
\text { (TLR) by either PCl } \\
\text { or CABG at } 8 \\
\text { months }\end{array}$ & $\begin{array}{l}\text { MACE including } \\
\text { cardiac death, MI, } \\
\text { or target vessel } \\
\text { revascularisation } \\
\text { (TVR) at } 12 \text { months }\end{array}$ & $\begin{array}{l}\text { MACE including } \\
\text { cardiac death, target } \\
\text { vessel MI, or clinically } \\
\text { driven TLR at } 1 \text { year }\end{array}$ & $\begin{array}{l}\text { Loss of FFR at } \\
\text { 8-month } \\
\text { follow-up }\end{array}$ & $\begin{array}{l}\text { Composite } \\
\text { of target } \\
\text { lesion failure } \\
\text { (TLF) } \\
\text { including } \\
\text { cardiac } \\
\text { death, target } \\
\text { vessel MI or } \\
\text { clinically } \\
\text { driven TLR at } \\
1 \text { year }\end{array}$ & $\begin{array}{l}\text { MACE including } \\
\text { cardiac } \\
\text { death, MI, or } \\
\text { ischaemia-driven } \\
\text { TVR at } 1 \text { year }\end{array}$ \\
\hline $\begin{array}{l}\text { Principal } \\
\text { findings }\end{array}$ & $\begin{array}{c}\text { MACE: } \\
24.4 \% \text { classic } \\
\text { crush } \\
11.4 \% \text { DK crush, } \\
p=0.02 \\
\text { TLR-free survival: } \\
75.4 \% \text { classic } \\
\text { crush } \\
89.5 \% \text { DK crush, } \\
p=0.002\end{array}$ & $\begin{array}{c}\text { MACE: } \\
\text { 17.3\% provisional } \\
\text { stenting } \\
\text { 10.3\% DK crush, } \\
p=0.070 \\
\text { Stent thrombosis: } \\
\text { DK crush } 2.2 \% \\
\text { provisional stenting } \\
0.5 \% \\
p=0.372\end{array}$ & $\begin{array}{c}\text { MACE: } \\
16.3 \% \text { culotte } \\
6.2 \% \text { DK crush, } \\
p<0.05 \\
\text { In-stent restenosis in } \\
\text { SB: } \\
12.6 \% \text { culotte } \\
6.8 \% \text { DK crush, } \\
p=0.037\end{array}$ & $\begin{array}{c}\text { Late (8-month) } \\
\text { loss in SB FFR: } \\
-0.06 \pm 0.11 \\
\text { DK crush } \\
-0.002 \pm 0.07 \\
\text { provisional } \\
\text { stenting } \\
\text { Acute gain in } \\
\text { SB FFR: } \\
0.18 \pm 0.15 \text { DK } \\
\text { crush }\end{array}$ & $\begin{array}{c}\text { TLF: } \\
\text { 10.7\% } \\
\text { provisional } \\
\text { stenting } \\
5.0 \% \text { DK } \\
\text { crush } \\
\text { (HR 0.42, } \\
95 \% \mathrm{Cl}: 0.21- \\
0.85, p=0.02 \text { ) } \\
\text { Target vessel } \\
\text { MI: }\end{array}$ & $\begin{array}{c}\text { MACE: } \\
\text { 18.1\% in both } \\
\text { groups (hazard } \\
\text { ratio: } 0.91, \\
95 \% \mathrm{Cl}: 0.48 \text { to } \\
\text { 1.88; } p=1.00 \text { ) } \\
\text { 1-year TVR: } \\
\text { 6.9\%, angio- } \\
\text { guided } \\
5.6 \%, \text { FFR-guided } \\
\text { ( } p=0.82 \text { ) }\end{array}$ \\
\hline
\end{tabular}




\begin{tabular}{|c|c|c|c|c|c|}
\hline & $\begin{array}{c}\text { Angiographic } \\
\text { restenosis: } \\
\text { MB: } \\
\text { DK crush 3.8\% } \\
\text { provisional stenting } \\
9.7 \% \\
p=0.036 \\
\text { SB: } \\
\text { DK crush } 4.9 \% \\
\text { provisional stenting } \\
22.2 \% \\
p<0.001 \\
\text { TVR: } \\
\text { DK crush } 6.5 \% \\
\text { provisional stenting } \\
14.6 \% \\
p=0.017\end{array}$ & $\begin{array}{l}\text { 3-year MACE results } \\
\text { later reported: } \\
\begin{array}{l}23.7 \% \text { culotte } \\
8.2 \% \text { DK crush, } \\
p=<0.001\end{array}\end{array}$ & $\begin{array}{c}0.12 \pm 0.18 \\
\text { provisional } \\
\text { stenting }\end{array}$ & $\begin{array}{c}2.9 \% \\
\text { provisional } \\
\text { stenting } \\
0.4 \% \mathrm{DK} \\
\text { crush, } \\
p=0.03 \\
\\
\text { Definite or } \\
\text { probable } \\
\text { stent } \\
\text { thrombosis: } \\
3.3 \% \\
\text { provisional } \\
\text { stenting } \\
0.4 \% \mathrm{DK} \\
\text { crush, } \\
p=0.02\end{array}$ & $\begin{array}{c}\text { 1-year stent } \\
\text { thrombosis: } \\
\text { 1.3\%, angio- } \\
\text { guided } \\
0.6 \%, \text { FFR-guided } \\
(p=0.56)\end{array}$ \\
\hline Limitations & \multicolumn{5}{|c|}{$\begin{array}{l}\text { While multicentre in nature, this series enrolled predominantly from China - there could be limits to generalising } \\
\text { findings to patients and practices outside of this region. } \\
\text { ? Intracoronary imaging guidance was not used in the majority of procedures, which could have optimised/altered } \\
\text { results in either arm. } \\
\text { ? Angiographic follow-up could have generated TLR events, though the aim was to wait until after the follow-up period if } \\
\text { possible. }\end{array}$} \\
\hline
\end{tabular}




\section{Moving image legend}

Moving image 1. Moving image showing abridged images of steps from a DK crush two-stent bifurcation $\mathrm{PCl}$ for a Medina 1,1,1 bifurcation lesion in the mid left anterior descending artery (LAD). The first image illustrates a significant lesion affecting the proximal to mid LAD and the first diagonal (D1). The MV and SB were both wired and predilated. Predilation led to small dissections in both vessels which were diseased and of relatively small calibre. The second image shows a stent being deployed in the diagonal with protrusion into the LAD. A balloon is positioned in the $L A D$, ready for SB stent crushing. The third moving image shows crushing of the SB stent; in this case, the SB wire was intentionally jailed. The fourth moving image shows the first kissing inflation of the DK crush after SB re-wiring and eventual passage of a balloon through the crushed stent, which required initial predilation with a $1.25 \mathrm{~mm}$ balloon. The fifth moving image shows deployment of the LAD stent. At this point, the diagonal wire had been removed. The sixth moving image shows the second kissing balloon inflation, which was completed after POT of the LAD stent and after re-wiring of the SB and passage of an SB balloon. The seventh moving image shows re-POT of the MV stent. The eighth moving image shows the final result. 